\title{
Um Protocolo para Comunicação entre Aeronaves não Tripuladas e Estações de Solo
}

\author{
André Alves Dos Reis, Bruno César Vani, Kleber Manrique Trevisani \\ Instituto Federal de Educação, Ciência e Tecnologia de São Paulo (IFSP) - Campus de \\ Presidente Epitácio - Rua José Ramos Júnior, 27-50 - Jardim Tropical, Presidente Epi- \\ tácio - São Paulo. \\ andrereis_live@hotmail.com, brunovani@ifsp.edu.br, kleber@ifsp.edu.br
}

\begin{abstract}
This paper presents the development of a communication protocol that coordinate communication between unmanned aircraft and ground stations. This protocol defines structures of the messages involved in this context, which allow controlling aircraft with different characteristics.
\end{abstract}

Resumo. Este trabalho apresenta o desenvolvimento de um protocolo de comunicação para coordenar a comunicação entre aeronaves não tripuladas $e$ estações de solo. O protocolo de comunicação desenvolvido define estruturas de mensagens envolvidas neste contexto, que possibilitam o controle de aeronaves com diferentes características.

\section{Introdução}

Os Veículos Aéreos Não Tripulados (VANTs) são aeronaves sem tripulação que podem ser remotamente pilotadas ou autônomas, cuja utilização não seja meramente recreativa (STEINER, 2012; ANAC, 2012). Seu principal objetivo é realizar missões aéreas para reduzir custos e/ou riscos em comparação com operações realizadas por aeronaves tripuladas (NERIS, 2001). Como não necessitam de tripulação, os VANTs podem realizar missões que seriam impossíveis ou mais custosas para aeronaves tripuladas, como por exemplo, monitorar locais de difícil acesso.

Segundo Amaral, Nascimento Jr. e Adabo (2009) a operação ou monitoramento de um VANT requer a integração de três segmentos: segmento aéreo, segmento de comunicações e segmento de solo. O segmento aéreo refere-se a uma aeronave, incluindo toda sua estrutura física e os sistemas embarcados, podendo variar seu tipo de acordo com sua necessidade de aplicação (PASTOR; LOPEZ; ROYO, 2007). O segmento de solo é composto pela estação de controle de solo (Ground Control Station, GCS), que permite a visualização dos dados de voo pelo piloto e o envio de comandos e dados de planejamento dos voos autônomos para a aeronave (AUSTIN, 2010). O segmento de comunicações interliga os segmentos aéreo e de solo através de um enlace de dados em que podem ser transmitidos a telemetria (dados de voo enviados da aeronave para estação de solo), os comandos (enviados da estação de solo para a aeronave) e sinais de vídeo (da aeronave para a estação de solo). Este segmento engloba os transceptores de radiofrequência e os protocolos de comunicação utilizados.

Este trabalho apresenta o desenvolvimento de um protocolo de comunicação que permite a comunicação entre uma GCS e um VANT. O protocolo desenvolvido foi definido em nível da camada de enlace de dados em relação ao modelo de referência ISO/OSI (TANENBAUM; WETHERALL, 2010). Foram definidas regras de 
delimitação de quadros, checagem de erros e as regras do protocolo para transmissão de telemetria e de telecomandos. O cenário de operação de um VANT pode incluir um canal de transmissão de sinais de vídeo, contudo, este tipo de transmissão não faz parte do escopo deste trabalho.

\section{Descrição do Protocolo}

O protocolo desenvolvido prevê a transmissão de dados entre a aeronave e o GCS. Dois grupos de dados são definidos: dados de telecomando e dados de telemetria.

O grupo de dados de telecomando possui quatro tipos de quadros: Quadro de Requisição de Configuração, Quadro de Configuração, Quadro Habilita Controle e Quadro de Telecomando. O Quadro de Requisição de Configuração é enviado da GCS para a aeronave, por solicitação do operador, para requisitar um Quadro de Configuração. O Quadro de Configuração, por sua vez, é enviado da aeronave para a GCS e descreve todos os controles da aeronave, incluindo suas características, que poderão ser manipulados pela estação de solo. Este quadro é importante, pois permite que uma GCS possa manipular aeronaves de diferentes tipos e configurações.

O Quadro Habilita Controle é enviado, inicialmente, da GCS para a aeronave, para solicitar uma permissão de controle, quando o operador deseja assumir o controle manual da aeronave. É importante evidenciar que não foi contemplada no desenvolvimento deste trabalho um quadro específico para realizar uma solicitação de voo autônomo. Contudo, dentro do Quadro Habilita Controle foi definido um atributo que define se o controle será realizado manualmente, pelo operador da GCS, ou autônomo, conforme plano de voo definido. Por fim, os Quadros de Telecomando, enviados da GCS para a aeronave, são montados de acordo com as configurações definidas no Quadro de Configuração. Dessa forma, o protocolo possibilita o envio dos comandos seguindo o formato especificado pela aeronave.

O grupo de dados de telemetria possui apenas um tipo de quadro: o Quadro de Telemetria. Esse quadro contém dados, transmitidos de forma contínua e repetitiva para a GCS, que permitem ao operador controlar a aeronave remotamente de forma segura ou monitorar um voo autônomo. Tais dados dependem da leitura contínua de dispositivos embarcados na aeronave, tais como giroscópios, barômetros, sensores de pressão e receptores posicionamento GNSS.

A técnica utilizada para delimitar os quadros é denominada byte stuffing. Tal técnica consiste em inserir bytes no início e fim de cada quadro para que fique explícito ao receptor onde inicia e onde termina cada quadro, permitindo assim contornar possíveis problemas de sincronizarão dos quadros em caso de problemas na transmissão. Para a detecção de erros, foi utilizado o algoritmo CRC-16 (Cyclic Redundance Code de 16 bits) (TANENBAUM; WETHERALL, 2010). Embora o protocolo de comunicação possua cinco tipos de quadros diferentes, todos seguem uma mesma estrutura: seu cabeçalho e rodapé permanecem idênticos para todos os quadros. Devido a limitação de espaço, detalhes sobre o formato dos quadros serão omitidos. 


\subsection{Lógica do Protocolo}

Antes e durante um voo, é necessário que a aeronave e a GCS realizem trocas de quadros definidos pelo protocolo de comunicação desenvolvido, em uma sequência lógica definida. A Figura 1 demonstra essa sequência lógica.

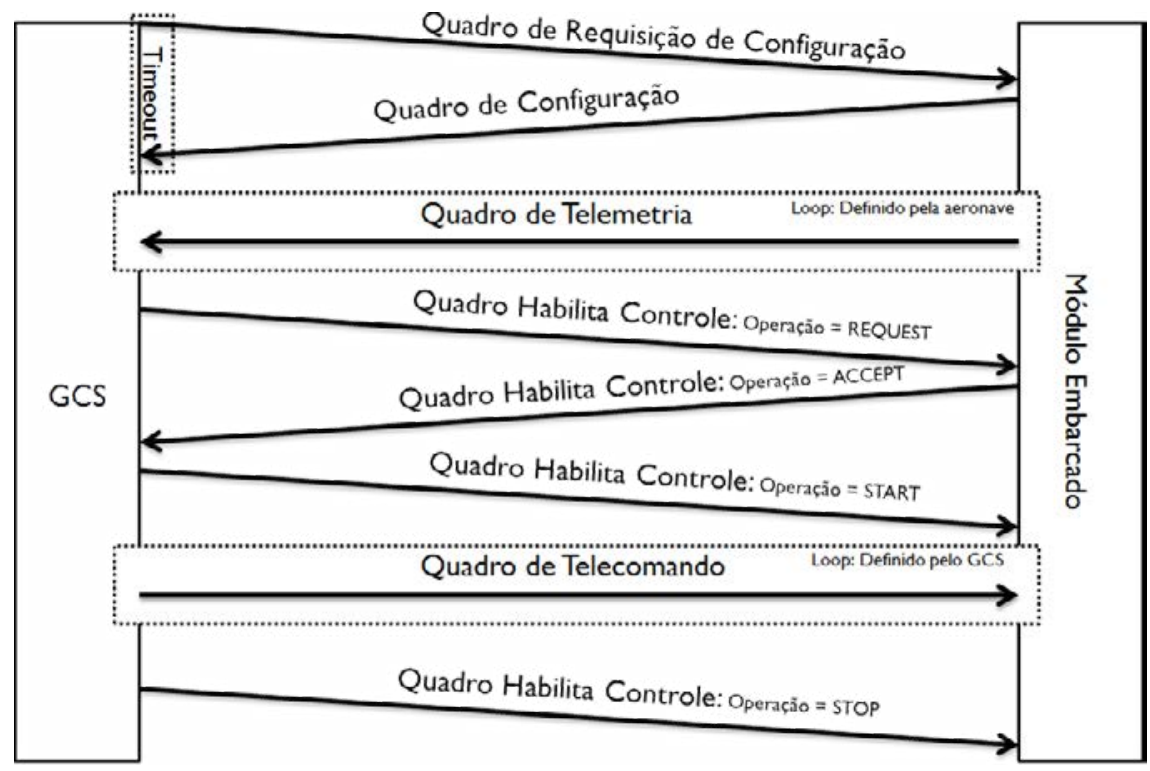

Figura 1. Troca de Quadros.

Inicialmente, a GCS envia uma solicitação de configuração inicial utilizando um Quadro de Requisição de Configuração e espera que a aeronave envie um Quadro de Configuração. Um timeout é definido na GCS para solicitar uma possível retransmissão em caso de falha no estabelecimento da comunicação (serviço confiável). Após o recebimento do Quadro de Configuração, a GCS conhecerá as configurações da aeronave e passa a receber os Quadros de Telemetria.

Quando solicitado pelo operador, a GCS transmite o Quadro Habilita Controle com o atributo Operação contendo o valor REQUEST. A aeronave responde com o mesmo tipo de quadro com o campo Operação contendo o valor $A C C E P T$. Por fim, a GCS encaminha outro quadro com o valor do campo Operação alterado para START. Este fluxo indica que a GCS solicita à aeronave a concessão dos comandos; a aeronave aceita o pedido e o GCS conclui o processo indicando que está iniciando o controle. A partir desse momento os Quadros de Telecomando podem então ser encaminhados para a aeronave.

Destaca-se que há um serviço confiável para os comandos com necessidade de confirmação, que podem ser úteis para acionamento, por exemplo, de câmeras, paraquedas e gaiolas. Já os comandos relacionados ao controle da aeronave não necessitam ser confirmados, pois o mais importante é a fluência dos comandos. A utilização de um serviço confiável apenas quando necessário implica diretamente em uma melhor utilização da largura de banda disponível. Eventualmente, para que o controle seja reestabelecido para um transmissor de rádio controle, por exemplo, o operador solicitará que o GCS desabilite o comando da aeronave, logo o GCS transmitirá um Quadro Habilita Controle com o valor STOP no atributo Operação. 


\section{Considerações Finais}

A proposta realizada por este trabalho contempla o desenvolvimento de um protocolo para controlar a comunicação entre uma GCS e uma aeronave. Tal protocolo permite o controle de aeronaves com características variadas e demonstrou ser capaz de ser utilizado para controlar um VANT a partir de uma GCS. Nos testes realizados o protocolo se comportou da maneira esperada, porém é necessária uma certa cautela sobre a capacidade de processamento e limites de memória nos sistemas embarcados onde o protocolo é implementado. Devido a flexibilidade do protocolo permitir o controle de aeronaves com diferentes configurações, alguns quadros não possuem tamanho definido (tamanho dinâmico), isso implica em mais processamento e alocação memória.

O contexto deste trabalho envolveu características que não foram possíveis de serem implementadas, mas não foram significativamente relevantes para a fase atual de desenvolvimento. Uma característica desejável e não implementada é a possibilidade da aeronave informar a GCS sobre quais serão os dados de telemetria transmitidos, permitindo que a mesma represente somente os dados enviados.

Algumas melhorias também podem ser implementadas em projetos futuros, como por exemplo, a implementação de algoritmos de criptografia de dados para evitar quebras de confidencialidade e integridade. Também se sugere a investigação de métodos de autenticação, como por exemplo, certificação digital, para que a GCS possa autenticar-se de forma segura antes de controlar a aeronave.

\section{Referências}

ANAC - AGÊNCIA NACIONAL DE AVIAÇÃO CIVIL. Instrução Suplementar: IS 21-002A. 2012.

AMARAL, G. F.; NASCIMENTO JR, C. L.; ADABO, G. J. Predição e Melhoria da Confiabilidade do Sistema de Controle de Voo de um Veículo Aéreo Não-Tripulado. In: 2009 Brazilian Symposium on Aerospace Eng. \& Applications / 3o CTA-DLR Workshop on Data Analysis \& Flight Control, 2009, São José do Campos. Anais... São José do Campos, 2009.

AUSTIN, R. Unmanned Aircraft Systems: UAVs Design, Development and Deployment. 1. ed. Reino Unido: John Wiley \& Sons Ltd. 2010.

NERIS, L. O. Um Piloto Automático para as Aeronaves do Projeto ARARA. 2001. 113 f. Dissertação (Mestrado) - Instituto de Ciências Matemáticas e de Computação - Universidade de São Paulo, São Carlos.

PASTOR, E; LOPEZ, J; ROYO, P. A Hardware/Software Architecture for UAV Payload and Mission Control. In: Digital Avionics Systems Conference, 2006 IEEE/AIAA, 25, 2006, Portland. Anais... Portland: IEEE, 2006. p. 1-8.

STEINER, E. M. Gerenciamento de Configuração de uma Linha de Produtos de Software de Veículos Aéreos não Tripulados. 2012. 121 f. Dissertação (Mestrado) - Instituto de Ciências Matemáticas e de Computação, Universidade de São Paulo, São Paulo.

TANenbaum, A. S.; WeTheralL, D. J. Computer Networks. 5. ed. Pearson Prentice Hall, 2010. 